Proceedings of XIX International Scientific Conference "New Technologies and Achievements in Metallurgy, Material Engineering, Production Engineering and Physics", Częstochowa, Poland, June 7-8, 2018

\title{
Investigations of Anti-Wear Coatings in Terms of Their Applicability to Tools in the FSW Process
}

\author{
W. WIECKOWSKI ${ }^{a, *}$, P. WIECZOREK ${ }^{b}$ AND J. LACKI ${ }^{b}$ \\ ${ }^{a}$ Czestochowa University of Technology, Faculty of Mechanical Engineering and Computer Science, \\ Institute of Mechanical Technologies, al. Armii Krajowej 21, 42-201 Czestochowa, Poland \\ ${ }^{b}$ Czestochowa University of Technology, Faculty of Production Engineering and Materials Technology, \\ Institute of Materials Engineering, Czestochowa, Poland
}

\begin{abstract}
The tools used in the process of friction stir welding wear gradually, which is one of the causes of joint defects. Instead of using expensive wear-resistant materials for tools, tool life can be extended by using antiwear tribological coatings. Due to huge development that has been observed in coating technologies, correct choice of a coating should be based on a series of tests in order to evaluate both mechanical and tribological properties. The aim of this study was to evaluate surface thickness and morphology and resistance to wear of commercial anti-wear coatings such as TiAlN, TiN, TiCN and AlCrN, deposited on hot work steel X40CrMoV5-1 as a base material. Examinations of coatings were conducted in order to explore potential opportunities for their use in tools, designed for the process of friction stir welding of aluminium alloy 7075 T6 to improve tool life. The scratch test method was used to evaluate the adhesiveness of coatings to the base material. Tribological properties of the examined coatings were evaluated based on the results of the examinations obtained on T-01 pin-on-disc tester and T-05 block-on-ring testers. The results of tribological tests conducted under dry friction conditions demonstrated that the highest resistance to abrasive wear among the coatings examined was found for the AlCrN.
\end{abstract}

DOI: 10.12693/APhysPolA.135.177

PACS/topics: friction, wear, anti-wear coatings

\section{Introduction}

Friction stir welding (FSW) technology was developed in the early nineties of the 20th century in the Welding Institute in the UK. One benefit of this method is opportunity to produce joints without defects and with good mechanical and structural properties, which caused that FSW technology has been used in many industries, including aviation and aerospace industries. FSW tool is exposed to wear during welding. Tool wear, which is reflected by the change in geometry and is caused by mechanical and thermal load to the working surface of the tool, results from abrasion, plastic deformation, oxidation, adhesion, chipping, etc. Manifested in the change of tool shape, excessive wear changes the likelihood of defects and deterioration of joint quality. This can be prevented by using appropriately selected process parameters, right material and anti-adhesive and anti-wear coatings. Excessive tool wear elevates the risk of defects and deteriorates joint quality. Furthermore, particles of worn tool material are transferred to the joint material. However, defects that result from presence of tool material in the joint occur more often in the case of tools with coatings. In some applications, inclusions in the joints are acceptable, whereas in others, tool particles present in the joint or in the coating have disadvantageous effect

\footnotetext{
* corresponding author
}

on joint properties and cannot be accepted. Furthermore, they might promote formation of local corrosion cells $[1-7]$.

Both materials and coatings used in FSW tools should be characterized by resistance to abrasive wear, adhesive, diffusive, and chemical wear. Additionally, good thermal properties are needed in the processes where substantial amount of heat is generated from tool material.

Mechanisms of wear of FSW tools depend on interactions between the welded piece and tool material, selected tool geometry and welding parameters. Wear, resulting from the interaction between tool working surface and base material, represents a kind of tribological system where mass, structure and physical properties of surface layers in contact are modified. Mass defects or changes in friction element dimensions, which represent the measure of wear, reflect susceptibility of the material to wear during contact with the weld material and its life [1, 3, 8-13]. Therefore, improvement in functional properties of tools is mainly connected with the development of new grades of materials for tools, right choice of their chemical composition, use of modern methods and manufacturing technologies and development of techniques of deposition of thin protective (anti-adhesive, anti-wear) coatings.

Due to the variety of working conditions, tool design and dominant type of wear, technological coatings that have been used to enhance tribological properties have to be deposited using specific manufacturing methods. The coatings tend to differ in their properties as they are 
manufactured by means of different technologies or are deposited on different base materials [14, 15]. For these reasons, further research is needed, aimed to evaluate mechanical and tribological properties of coatings in order to choose an optimal coating for a concrete application. Therefore, right choice of a coating requires the analysis of conditions in which the coating is expected to be used and several experiments have to be performed [1624]. An adequately chosen and deposited surface layer allows for manufacturing tools from materials with poorer functional properties (usually cheaper) and obtaining improved functional properties of tool surfaces, which typically leads to more favourable tribological properties of friction surfaces and enhanced tool reliability (life) while reducing failure rate.

Adesina et al. presented the results of the examinations of wear of steel tool with AlCrN coating in the process of FSW welding of aluminium alloy 6061-T6. The researchers demonstrated the usefulness of the coating, which both limited tool wear and helped obtain the joint without many substantial defects [23].

Literature reports provide information about the use of anti-wear coatings in FSW tools. However, few details have been published on life of such coatings. Casalino et al. examined the effect of geometry, tool resistance and surface state on friction stir welding of aluminium alloy $5754 \mathrm{H} 11$. The anti-wear AlCrN coating examined by these researchers made of wolfram carbide allowed for obtaining a joint which was nearly defect-free. However, the authors failed to provide information about the effect of coating on life of the tool studied [25].

Some studies have examined the effectiveness of the use of $\mathrm{TiC}$ and $\mathrm{TiN}$ coatings in ceramic $\mathrm{Si}_{4} \mathrm{~N}_{4}$ tools for friction stir welding of steel. The coatings were deposited on the tool in order to eliminate contamination of the weld with wear products. However, no information was published on the life of coatings used $[12,26]$.

Batalha et al. presented the results of examinations of wear of an AlCrN on a surface of the FSW tool made of cemented carbides in the process of titanium welding. Due to heavy-duty operating conditions, the coating was completely worn, thus failing to meet the expectations in terms of improvement of the life of the tool studied [21].

Information about the use of anti-wear coating made of boron carbide $\mathrm{B}_{4} \mathrm{C}$ in tools made of tool steel for friction stir welding of metal matrix composites (MMCs) $\mathrm{Al}$ $6092 / 17.5 \% \mathrm{SiC} / \mathrm{T}-6$ was presented by Bhat et al. The authors did not present, however, information about potential improvements in tool life due to the use of the coating [27].

Devanatha et al. obtained enhanced life of steel tools used for FSW processes of welding metal matrix composite materials using the anti-wear TiAlN coating [28].

\section{Goal and scope of work}

The aim of the study was to evaluate roughness parameters, tribological properties and resistance to tribological wear of selected technical coatings deposited on the specimen's base material. Furthermore, the study also aimed to chose the coating for further wear tests of FSW tools with deposited protective coating conducted in industrial conditions to identify opportunities of its use in order to extend tool life in FSW/FSSW welding of aluminium $7075 \mathrm{~T} 6$.

The first stage was to determine the thickness of the obtained coatings. The measurements were made on a cross-section using secant lines. Further part of examinations was focused on parameters of coating roughness. An atomic force microscope (Veeco Nanoscope V) was used, with scanning area of $100 \mu \mathrm{m}^{2}$. The following parameters were determined: $R_{a}, R_{q}, R_{\max }$ and surface area difference (SAD).

Significant information about the usefulness of the material and coatings for tools for FSW processes can be provided by friction-wear profiles for the materials studied obtained during tribological tests. Material testing performed by means of tribological testers allow for measurements of movement resistance (friction forces) and wear of elements of the friction pair (specimens and counter-specimens).

The examinations were performed for four types of commercial anti-wear coatings: TiN (Balinit A), TiCN (Balinit B), TiAlN (Balinit Futura Nano Top) and AlCrN (Balinit Alcrona Pro) that have been used to extend life of tools for processing metals working under conditions of high mechanical and thermal loads. Choosing of coatings was done on specification from manufacturers and predicted environmental conditions. Coatings were deposited on the working surface of the specimens in Oerlikon Balzers Coating Sp. z o.o. by PVD (Arc). The coatings were disc-shaped and block-shaped and made of hot work steel X40CrMoV5-1 after thermal treatment in order to obtain hardness of 50 HRC. Before deposition, the working surfaces of the coatings were ground.

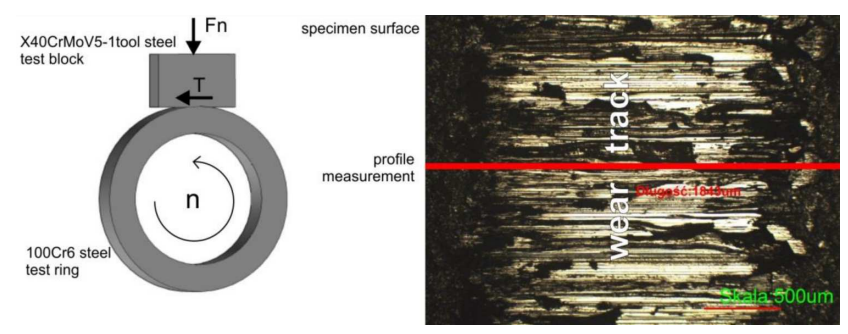

Fig. 1. T-05 block-on-ring wear test and wear track formed on the X40CrMoV5-1 tool steel specimen surface during sliding wear test.

Evaluation of tribological properties of the examined coatings was performed using the tribological T-05 rollblock tester with the contact focused on the friction distance of $50 \mathrm{~m}$ and sliding speed of $0.1 \mathrm{~m} / \mathrm{s}$ and load of $50 \mathrm{~N}$ (Fig. 1).

In friction and wear examinations we used the T-01 pin-on-disc tester under conditions of dry friction at sliding speed of $0.1 \mathrm{~m} / \mathrm{s}$ and pin load of $20 \mathrm{~N}$. The examined specimens in the form of discs were in contact 


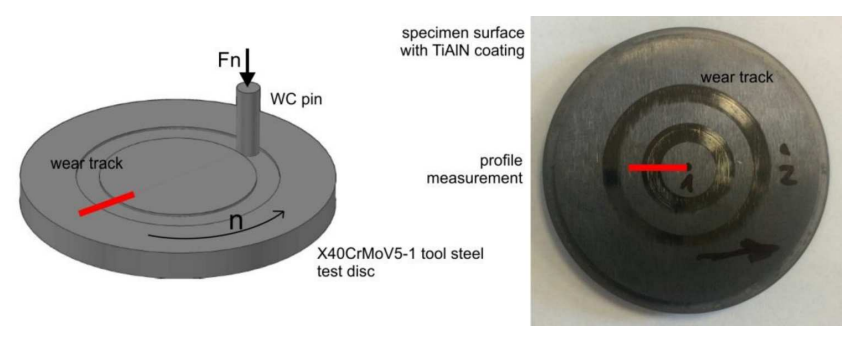

Fig. 2. T-01 pin-on-disc wear test and wear track formed on the X40CrMoV5-1 tool steel specimen surface with TiAlN coating during sliding wear test.

with $2.5 \mathrm{~mm}$ pin made of wolfram carbide. The friction and wear examinations were performed in the ambient temperature, with the number of specimen rotations of 100,000. Coefficient of friction between the pin and the disc was measured (see Fig. 2).

The degree of wear of the coatings deposited on the specimen surface was determined based on the measurements of the depth of transverse friction marks in the cross-section by means of the contact measurements using the TALYSURF 120 profilometer (Taylor Hobson). Observation of the wear marks following the friction and wear tests were performed using the digital microscope.

The adhesiveness of the examined coating was evaluated by means of the scratch test. For this purpose the Revetest Xpress (CSM Instruments) system with Rockwell diamond intender (radius $200 \mu \mathrm{m}$ ) was used. The load of the indenter was increased gradually from 1 to $100 \mathrm{~N}$ at the distance of $10 \mathrm{~mm}$, with specimen movement velocity of $6.06 \mathrm{~mm} / \mathrm{min}$. Scratches on the surface were observed under the optical microscope.

\section{Results}

Table 1 presents the results of the measurements of thickness of individual coatings. The TiAlN coating thickness differed significantly from other coatings. The coatings made of nitride or titanium carbonitride were of the same thickness.

TABLE I

Thickness measurement results.

\begin{tabular}{c|c|c|c|c}
\hline \hline \multicolumn{1}{c|}{ Designation } & TiAlN & TiN & TiCN & AlCrN \\
\hline thickness $[\mu \mathrm{m}]$ & 7.94 & 2.45 & 2.53 & 1.63 \\
standard deviation $[\mu \mathrm{m}]$ & 0.07 & 0.18 & 0.05 & 0.05
\end{tabular}

Figure 3 presents the $3 \mathrm{D}$ view of the representative locations of the deposited coatings. Roughness parameters are presented in Fig. 4.

Analysis of the values of roughness parameters reveals that the smoothest surface was obtained for titanium carbonitride. This was also confirmed by the SAD parameter, which was $c a .4 .3 \%$, similar to that for nitride coating (Fig. 5). Other two coatings were characterized by higher roughness and over four times higher degree of SAD.
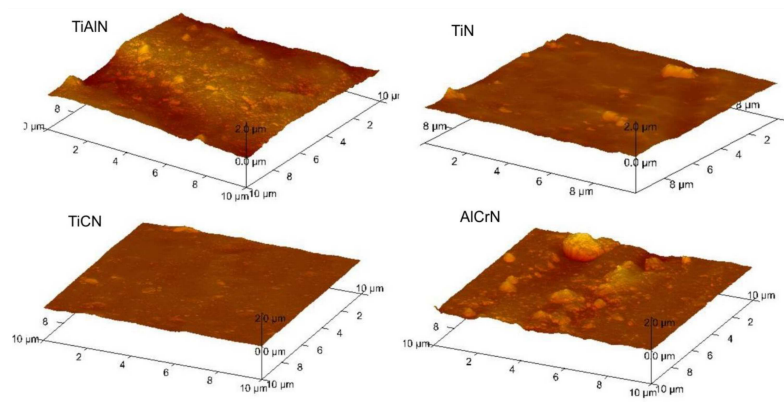

Fig. 3. Coating surface $-3 \mathrm{D}$ view.

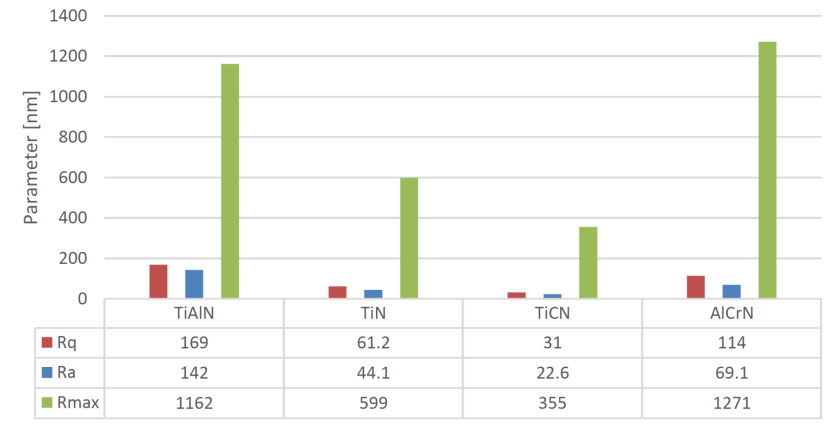

Fig. 4. Roughness parameters of investigated coatings.

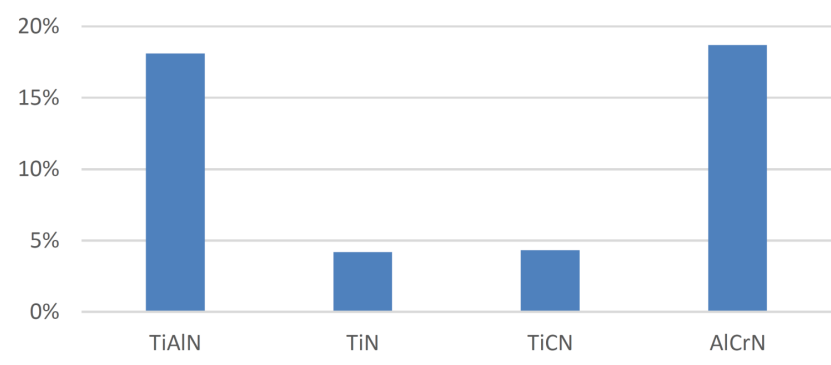

Fig. 5. Surface area difference for the coatings examined in the study.

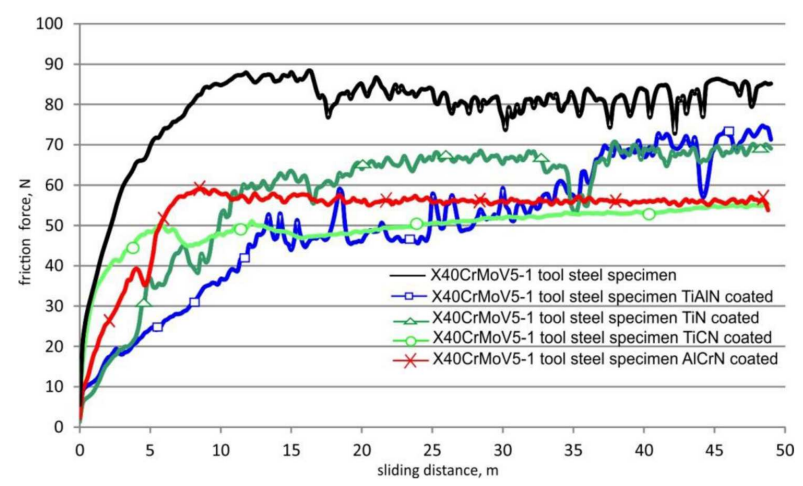

Fig. 6. The plot of friction force changes versus the sliding distance during block-on-ring wear test. 


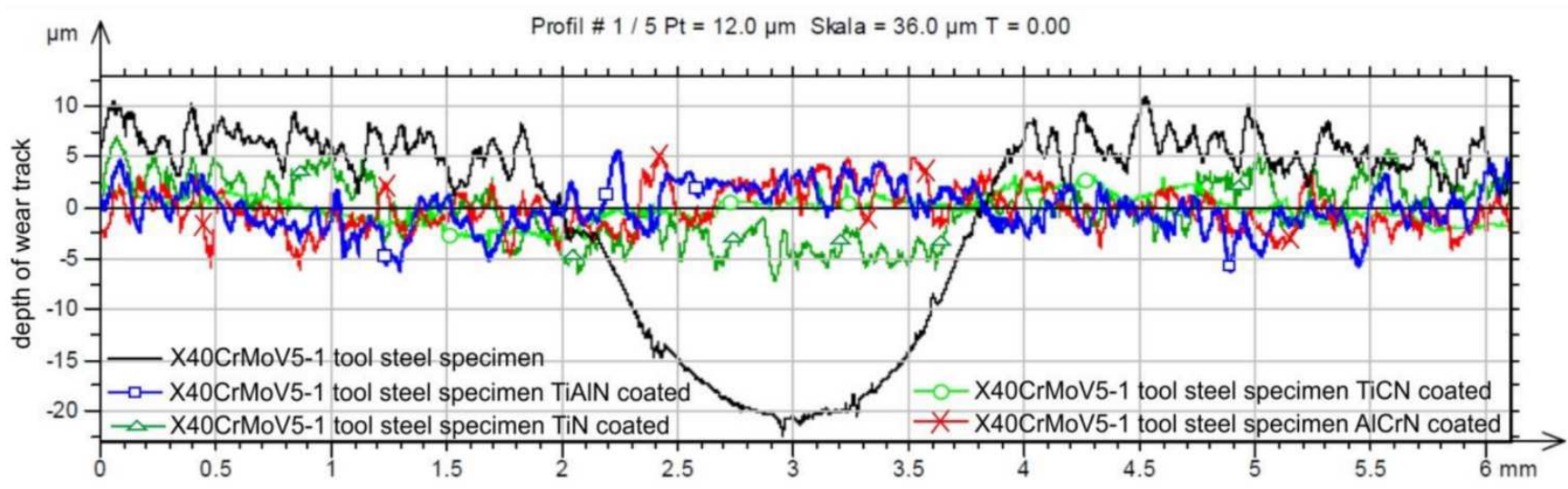

Fig. 7. Wear tracks profile formed on the specimen surface during block-on-ring wear test.
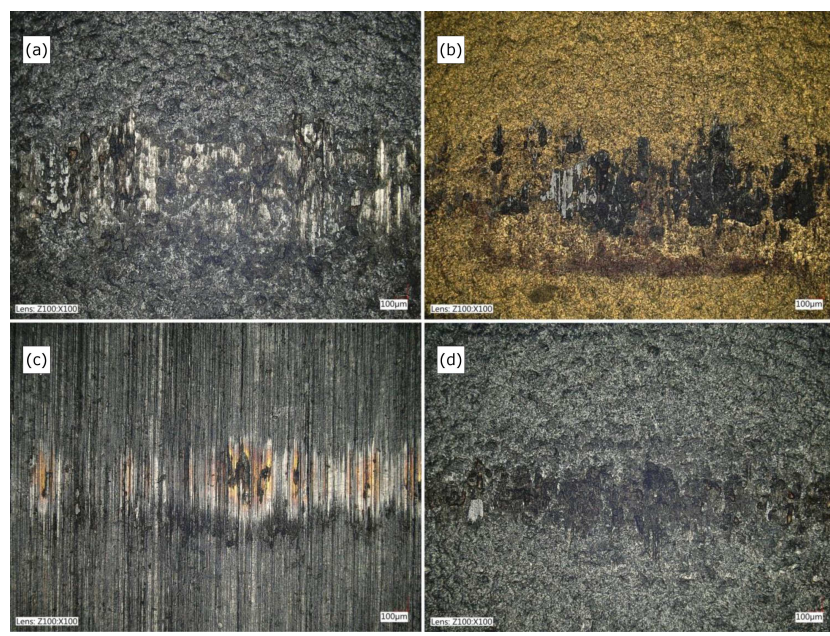

(d)

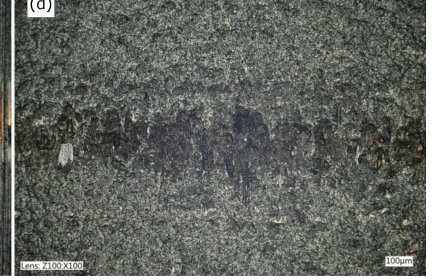

Fig. 8. View of wear track formed on the X40CrMoV5-1 tool steel specimen surface during sliding wear test: (a) TiAlN coated, (b) TiN coated, (c) TiCN coated, (d) AlCrN coated.

The results of friction and wear examinations using the T-05 tester, including profiles and values of friction force and visual assessment of friction marks both on the steel surface of the specimens and counter-specimens indicated intensive abrasive wear of both friction pair elements.
The recorded friction force profiles for the examined pairs vs. friction distance are presented in Fig. 6 .

The use of all examined anti-wear coatings caused a reduction in friction force and substantially limited wear of steel surface area, which was confirmed by the measurements of friction mark profile on the sample surface (Fig. 7).

Gradual increase in friction force during the test indicates the progressing wear of TiAlN and TiN coating. The state of the friction surface after completion of the examinations with noticeable areas of coating damages are presented in Fig. 8. Among the coatings, the smallest wear marks were found on the $\mathrm{AlCrN}$ coating, which ensured a constant value of friction force during the test and, therefore, invariable parameters of the friction pair.

The results of the examinations of the coating wear using the pin-on-disc method are consistent with the results of the examinations obtained during friction and wear test using the block-on-ring tester. The examinations demonstrated varied wear of the examined coatings. As can be concluded from the results of the measurements of the cross-section of the friction mark, the highest resistance to abrasive wear was found for the AlCrN coating. Furthermore, the highest wear intensity was observed for the TiAlN and TiN coatings (Fig. 9).

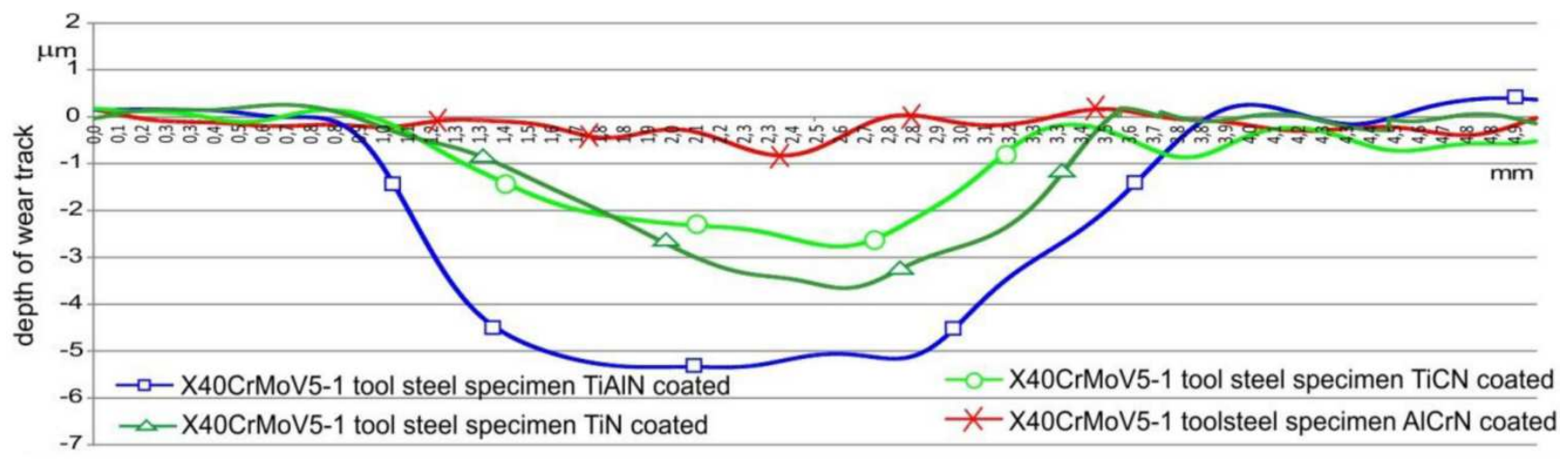

Fig. 9. Wear tracks profile formed on the specimen surface during pin-on-disc wear test. 

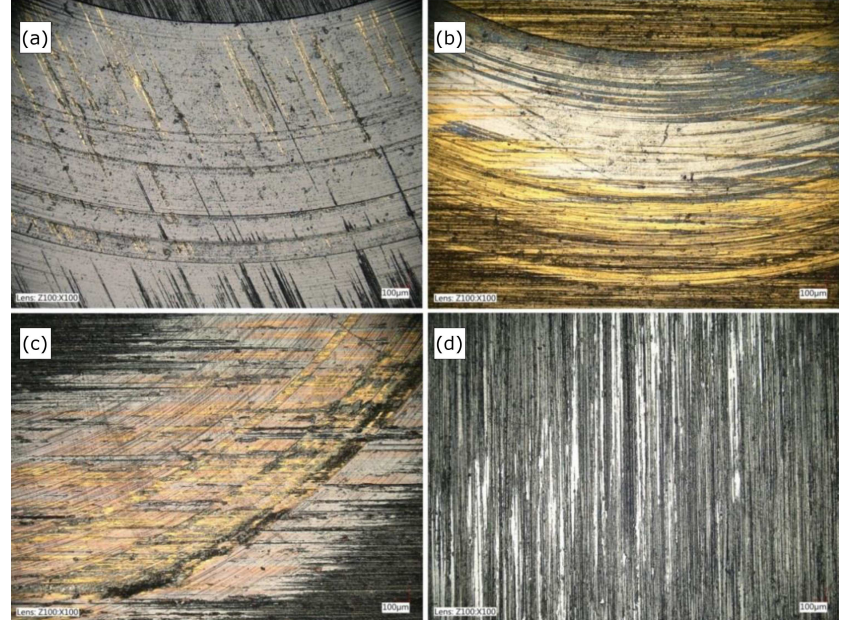

Fig. 10. View of wear track formed on the X40CrMoV5-1 tool steel specimen surface during pin-on-disc wear test: (a) TiAlN coated, (b) TiN coated, (c) TiCN coated, (d) AlCrN coated.

The friction mark on the surface of the specimens with deposited anti-wear coatings subjected to friction and wear examinations by means of the T-01 tester are presented in Fig. 10. All the coatings studied had wear marks, with the greatest degradation observed on TiN and TiCN coatings, whereas the best anti-wear properties were found for AlCrN coating.

The use of the examined anti-wear coatings led to changes in the conditions of friction expressed by means of the value of coefficient of friction for the materials used in the friction pair examined. The use of the anti-wear coatings led to the decreased value of coefficient of friction in the initial phase of the tests compared to what was observed during the examinations of the steel sample without coating, for which the value of coefficient of friction was changing over the narrow range of $0.35-0.45$. The study demonstrated that the value of coefficient of friction for each coating increased with the progressing wear process to the value similar to that recorded for the sample without coating. In the case of TiAlN coating, coefficient of friction ranged from 0.25 to 0.5 . For TiN, coefficient of friction was found to be from 0.2 to 0.4 . In the case of pin made of $\mathrm{WC}$, this value for the TiCN coating ranged from 0.25 to 0.4 . Examinations of the $\mathrm{AlCrN}$ coating revealed coefficient of friction of $0.25-0.45$.

The usefulness of the anti-wear coatings in terms of improvement in the life of FSW tools, apart from tribological properties and resistance to wear is also determined by their high adhesion to base material. Therefore, additional information about the examined coatings was provided by the results of examinations of coating adhesiveness. The scratch test at varied load of the indenter was used to evaluate values of critical load $L_{c} 2$ that characterizes adhesiveness of the coatings. The highest critical load $L_{c} 2$ of $81 \mathrm{~N}$, followed by the destruction of the coating, was found for AlCrN. Other coatings were destroyed: TiAlN coating at the load of $46 \mathrm{~N}$, TiN at $78 \mathrm{~N}$ and TiCN - at $63 \mathrm{~N}$. The profiles of normal

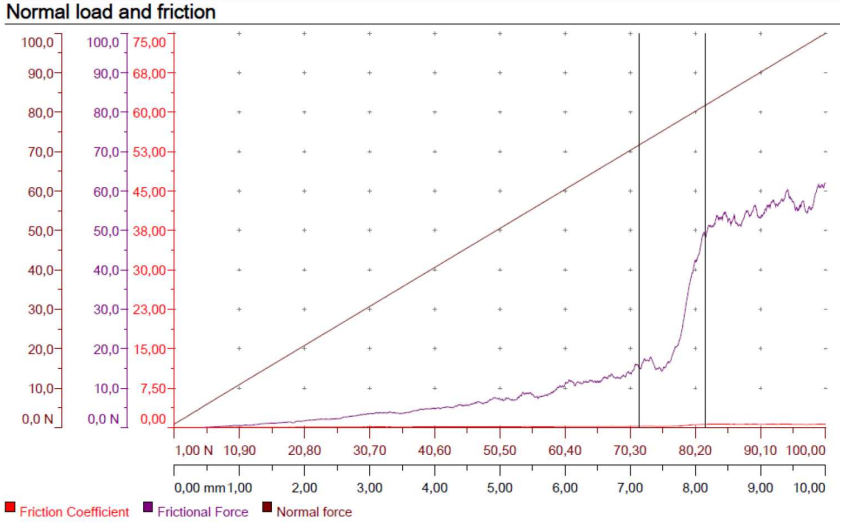

Fig. 11. Scratch test results of the X40CrMoV5-1 tool steel sample with AlCrN coating.
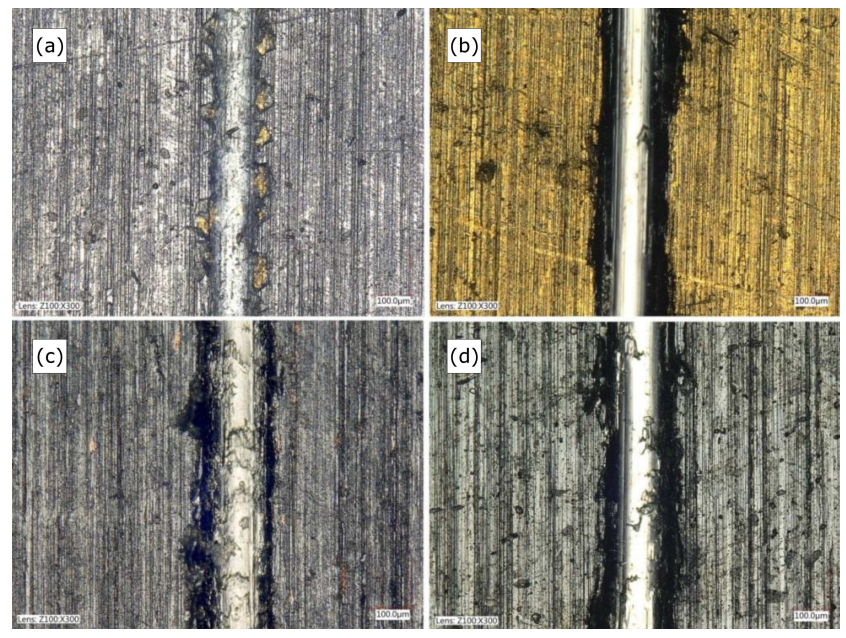

Fig. 12. View of coating damage during scratch test obtained with the Keyence digital microscope (a) TiAlN coating, (b) TiN coating, (c) TiCN coating, (d) AlCrN coating.

force $F_{N}$, friction force $F_{T}$, coefficient of friction $\mu$ and the images observed and recorded by the microscope in order to reveal the character of damages are presented in Figs. 11 and 12.

\section{Summary}

A noticeable differentiation in morphology is observed in the group of coatings studied between coatings containing aluminium and coatings without this element. The thickness of the coatings ranged from 1.63 to $7.94 \mu \mathrm{m}$. The lowest surface area difference was found for the coatings without aluminium. Nevertheless, their resistance to wear was the lowest among others. It was found based on the results of the tribological tests that the coatings are characterized by different abrasive wear. Examinations of the coating adhesiveness by means of the scratch test and examinations of their resistance to abrasive wear revealed the best tribological properties for the AlCrN coating. However, it should be remembered that the obtained results of the examination were significantly affected by such parameters as load of the friction 
pair and sliding speed, thickness of the coating, state of friction surfaces, and ambient conditions. Therefore, the results of friction and wear examinations should be approached as a comparative study. Furthermore, highly loaded working surfaces of tools are exposed to high mechanical loads and high working temperature. Therefore, it is advisable to conduct additional examinations, whose aim is to determine resistance of the coating to wear (determination of tribological properties) at elevated temperatures.

The life of the coatings examined (life of the combination of the layer with the base material) was also determined by the type of base material, especially preparation of the working surface of the specimens (surface roughness) on which the coating was deposited. Although higher surface area difference is conducive to stronger binding the coating to the base material, the visual assessment of the friction marks revealed that excessive roughness can lead to accelerated degradation of the coating and uncovering of the base material in area of large surface unevenness.

The use of the coatings examined, including $\mathrm{AlCrN}$ coating, led initially to the decrease and then to gradual increase of coefficient of friction, which determines the amount of heat generated in the friction pair. Therefore, the change in the conditions of friction caused by the use of a coating requires examinations towards the choice of optimal conditions of the FSW/FSSW welding for tools with anti-wear coatings. The change in the value of coefficient of friction during the functional use of a coating is an unfavourable phenomenon as it leads to changes in the conditions of the process of welding at unchanged, predefined welding parameters, which might lead to joint defects. Based on the results of the laboratory examinations obtained in the study, the $\mathrm{AlCrN}$ coating was chosen for further examinations conducted in industrial conditions and aimed to evaluate its usefulness for hot work steel in the process of FSW welding of aluminium 7075 T6 in terms of extending its functional life.

\section{Acknowledgments}

Financial support of The National Centre for Research and Development, European Union, PZL Mielec/a Sikorsky Company, in the framework of European Regional Development Fund Project "Advanced techniques for the fabrication of airframe structures using innovative friction stir welding (FSW) technology", no. INNOLOT/I/4/NCBR/2013 is gratefully acknowledged.

\section{References}

[1] G. Buffa, L. Fratini, F. Micari, in: Proc. NAMRI/SME, Notre Dame, Vol. 40, 2012.

[2] P. Lacki, W. Więckowski, P. Wieczorek, Archiv. Metall. Mater. 60, 2297 (2015).

[3] R. Burek, D. Wydrzyński, J. Sęp, W. Więckowski, Eksploatacja i Niezawodność 20, 100 (2018) (in Polish).
[4] A. Farias, G.F. Batalha, E.F. Prados, R. Magnabosco, S. Delijaicov, Wear 302, 1327 (2013).

[5] H.J. Liu, J.C. Feng, H. Fujii, K. Nogi, Int. J. Machine Tools Manufact. 45, 1635 (2005).

[6] P. Myśliwiec, R.E. Śliwa, R. Ostrowski, .

[7] S.R. Mishra, Z.Y. Ma, Mater. Sci. Eng. $R$ 50, 1 (2005).

[8] Y.N. Zhang, X. Cao, S. Larose, P. Wanjara, Canad. Metall. Quarterly 51, 250 (2012).

[9] L.A. Dobrzański, A.D. Dobrzańska-Danikiewicz, Open Access Library 5, 368 (2011) (in Polish).

[10] J.F. Hinrichs, C.B. Smith, B.F. Orsini, R.J. DeGeorge, B.J. Smale, P.C. Ruehl, Friction Stir Welding for the $21^{\text {st }}$ Century Automotive Industry, Friction Stir Link, Inc., Waukesha (WI).

[11] C.S. Ridges, M.P. Miles, Y. Hovanski, J. Peterson, R. Steel, "Wear testing of friction stir spot welding tools of DP 980 steel", in: Friction Stir Welding and Processing VI, Eds. R. Mishra et al., TMS, 2011.

[12] R. Rai, A. De, H.K.D.H. Bhadeshia, T. DebRoy, Sci. Technol. Weld. Join. 16, 325 (2011).

[13] P. Lacki, Z. Kucharczyk, R. Śliwa, T. Gałaczyński, Archiv. Metall. Mater. 58, 595 (2013).

[14] M. Kot, L. Major, J. Lackner, Mater. Des. 51, 280 (2013).

[15] J. Lackner, L. Major, M. Kot, Bull. Pol. Acad. Sci. Techn. Sci. 59, 343 (2011).

[16] L.A. Dobrzański, M. Polok, M. Adamiak, in: Proc. 12th Int. Sci. Conf. Achievements in Mechanical and Materials Enginering, 2003, p. 277.

[17] Á. Meilinger, I. Török, Product. Process. Syst. 6, 25 (2013).

[18] A. Gilewicz, B. Goluch, Z. Kukliński, Mechanik 5-6, 75 (2016) (in Polish).

[19] M. Michalak, R. Michalczewski, M. Szczerek, Inżynieria materiałowa 35, 527 (2014) (in Polish).

[20] P. Holubář, R. Janků, Magazyn Przemysłowy 115, 18 (2012) (in Polish).

[21] G.F. Batalha, A. Farias, R. Magnabosco, S. Delijaicov, M. Adamiak, L.A. Dobrzański, J. Achiev. Mater. Manufact. Eng. 55, 607 (2012).

[22] A. Rutkowska, M. Dąbrowski, Archiwum Odlewnictwa 6, No. 21 (2006) (in Polish).

[23] A.Y. Adesina, Z.M. Gasem, F.A. Al-Badour, J. Manufact. Process. 25, 432 (2017).

[24] Ł. Major, Archiv. Civil Mech. Eng. 14, 615 (2014).

[25] G. Casalino, S. Campanelli, M. Mortello, Proced. Eng. 69, 1541 (2014).

[26] H.K.D.H. Bhadeshia, T. DebRoy, Sci. Technol. Weld. Join. 14, 193 (2009).

[27] B.N. Bhat, R.W. Carter, R.J. Ding, K.G. Lawless, Friction Stir Welding Development at NASA - Marshall Space Flight Center, 2001.

[28] C. Devanatha, A.S. Babu, Proced. Mater. Sci. 6, 1470 (2014) 